\title{
THE RELATIONSHIP BETWEEN CALCIUM-PHOSPHORUS METABOLISM, THE 'KREBS CYCLE' AND STEROID METABOLISM
}

\author{
BY \\ ETTORE DE TONI, Jr. and SERGIO NORDIO \\ From the Department of Paediatrics, Gaslini Children's Hospital, Genoa University School of Medicine, Italy
}

(RECEIVED FOR PUBLICATION MARCH 6, 1959)

It has been shown in the course of the last few years that the number of factors playing a part in calcium-phosphorus (Ca-P) metabolism is far greater than had been known. It was found that the calcification of bones depends in the first place on the 'citric acid cycle' and on adenosine triphosphate (ATP) (oxidative phosphorylation) (Dickens, 1941 ; Albaum, Hirshfeld and Sobel, 1952; Dixon and Perkins, 1952; Marks, Hiatt and Shorr, 1953). Alkaline phosphatase intervenes chiefly in the processes concerned with the formation of the organic substance of the skeleton.

Some factors as yet unknown (citrates ?) similarly regulate the action of the parathyroid hormone, an action which has not yet been accurately defined (Zweymüller, 1958). The role played by the parathyroid in classical and in vitamin $D$ resistant rickets is still uncertain (Lamy, Royer, Frézal and Lestradet, 1958). Similarly, the action of vitamin $D$ seems to be dependent on factors which regulate the sensitivity of the organism to its effect (Fanconi and Spahr, 1956). The suprarenals have acquired some degree of importance, as was shown in studies on idiopathic hypercalcaemia, on tetany occurring in newborn infants of diabetic mothers and on hypercalcaemia with osteosclerosis found in a number of cases of myxoedema (Gittleman, Pincus, Schmerzler and Saito, 1956; Winberg and Zetterström, 1956; Anderson, Brewis and Taylor, 1957; Royer, Lestradet and Habib, 1958; Zetterström and Arnhold, 1958). Cortisone acts as an antagonist of vitamin $D$ by impairing the absorption of calcium from the intestines; another action of cortisone is to reduce the rate of tubular reabsorption of phosphorus (Roberts and Pitts, 1953). It is possible that there is a relationship between the suprarenals and the parathyroid glands, as suggested by cases of hypoparathyroidism associated with Addison's disease (Leonard, 1946; Papadatos and Klein, 1954; Whitaker, Landing, Esselborn and Williams, 1956).
We have become conversant in recent years with the importance of the relationship between ossification, parathyroid hormone, vitamin $\mathrm{D}$ and the 'Krebs cycle' (Glanzmann, Meier and Walthard, 1946; Heinz, Müller and Rominger, 1947; Harrison and Harrison, 1952a; Nordio, Semach and Grego, 1956; de Toni, 1957). In rickets the citric acid level in the blood and urine is diminished (Harrison, 1954; Nordio et al., 1956). The same phenomenon is observed in idiopathic hypercalcaemia (Forfar, Balf, Maxwell and Tompsett, 1956; Nordio et al., 1956). Administration of vitamin $D$ and, although less regularly, of parathormone leads to a rise in the citric acid level in blood and urine (Harrison and Harrison, 1952a; Steenbock and Bellin, 1953; Nordio et al., 1956). Considerable importance is attributed to the 'citric acid cycle' in the renal tubules in connexion with the regulation of the acid-base balance and the reabsorption of phosphorus, amino acids and glucose (Harrison and Harrison, 1941; Durand, Manzini, Bruni and Semach, 1956; Nordio et al., 1956). As is known, the synthesis of steroids has the 'Krebs cycle' as its starting point, and it may be possible to interpret the various disturbances of calcium-phosphorus metabolism also in terms of the Krebs cycle.

\section{Classical Rickets Treated with ATP}

We have studied the following four cases of classical rickets in the florid stage, no treatment with vitamin $\mathbf{D}$ ever having been given.

Case 1 was a boy aged 2 years 4 months; Case 2 was a girl aged 4 years 1 month (sister of Case 1); Case 3 was a boy aged 19 months, and Case 4 was a girl aged 13 months.

Treatment. All four cases received ATP intramuscularly, the dosage being, in Cases 1 and 2, $5 \mathrm{mg}$. daily for a period of 50 days and $10 \mathrm{mg}$. daily for a further period of 25 days; in Case $3,5 \mathrm{mg}$. daily for a 
period of 20 days and $10 \mathrm{mg}$. daily for a further period of 10 days; and in Case $4,5 \mathrm{mg}$. daily for a period of 40 days.

These were cases of classical rickets with hyperaminoaciduria and slight changes in the acidification of the urine. Results of treatment are shown in Table 1. The citrate content of the blood was markedly lowered in two cases only, in contrast to the other cases studied by Harrison (1954) and Nordio, Segni and Massaccesi, 1957. The citric acid content of the urine was not markedly lowered and in Case 2 it was even raised, whilst the figures for blood citric acid were low. Administration of ATP led to a definite improvement in the radiological picture of the bones (Figs. 1-4), to a rise in blood phosphorus, and in three instances to a lowering of the phosphatase figures. The changes in phosphaturia and in the citric acid levels in the urine and blood did not conform to any regular pattern, and the changes in urinary amino acids were only slight.

\section{Rickets and Sensitivity to Vitamin D}

Case 5. This boy, aged 18 months, had radiological and clinical signs of severe rickets. The main biochemical features were as follows: the blood citric acid level was markedly lowered with a comparative increase of urinary output of citric acid; there was a moderate lowering of the blood phosphorus level with normal urinary output of phosphorus, and a moderate rise in phosphatase (Table 2).

Treatment. After daily administration of 10,000 i.u. of vitamin $D_{2}$ over a period of 40 days the following findings were noted. There was an increase in calcification of the bones but severe deformities of the metaphyses were still present. There was a return to normal of the blood phosphorus but no change in phosphatase or citrate. After two months' treatment with ATP (10 mg. daily) the radiological picture became normal and there was some improvement in the phosphatase level. This case shows partial resistance to vitamin $D$ but complete clinical and radiological cure with ATP.

Cases 6 and 7. These twins, aged 17 months, had severe clinical and radiological signs of rickets. One sister had suffered from rickets and still showed signs of the disease. The radiological and biochemical findings in both twins were more or less identical.

The biochemical findings showed: a moderately low blood phosphorus level with slightly increased phosphaturia; a marked increase in phosphatase, increased amino-aciduria, considerable lowering of the blood citric acid level and marked hypercitruria (Table 2). Table 3 gives the blood and urine citric acid levels compared with normals.

In contrast to findings in normal subjects, intravenous loading with citric acid did not lead to any marked rise in the citric acid content of the blood (Fig. 5). The citric acid content of the urine before citric acid administration was 6.75 mg. per hour; after loading it was $32.4 \mathrm{mg}$. per hour.

By simultaneous determination of the endogenous creatinine clearance, we were able to show that the glomerular filtration rate of citrate was less than the final urinary excretion rate (Table 4). In a number of normal subjects of different ages and in other cases of rickets of the classical type we have always found the urinary excretion per minute of citric acid to be smaller than the glomerular filtration per minute. Our findings suggest a lowering of the renal threshold for citric acid in the twins. It appears that in these cases the renal tubules excrete rather than reabsorb citric acid. These studies show the existence in certain forms of rickets of a 'citric renal diabetes'.

The mother of the twins showed a very low blood citric acid level and a very high urinary citric acid output. Similarly, the sister of the twins, who was affected by rickets, showed a very low blood citric acid level (Table 5). The father and brothers, who were free from rickets, had normal blood citric acid levels. It seems that the marked familial predisposition to rickets was associated with a change in citrate metabolism.

Treatment. Case 6, following a single injection of $15 \mathrm{mg}$. $\left(600,000\right.$ i.u.) of vitamin $D_{2}$, was given 5,000 i.u. daily by mouth over a period of two months. We noted only a slight improvement in the radiological picture but the phosphorus content of the blood became normal
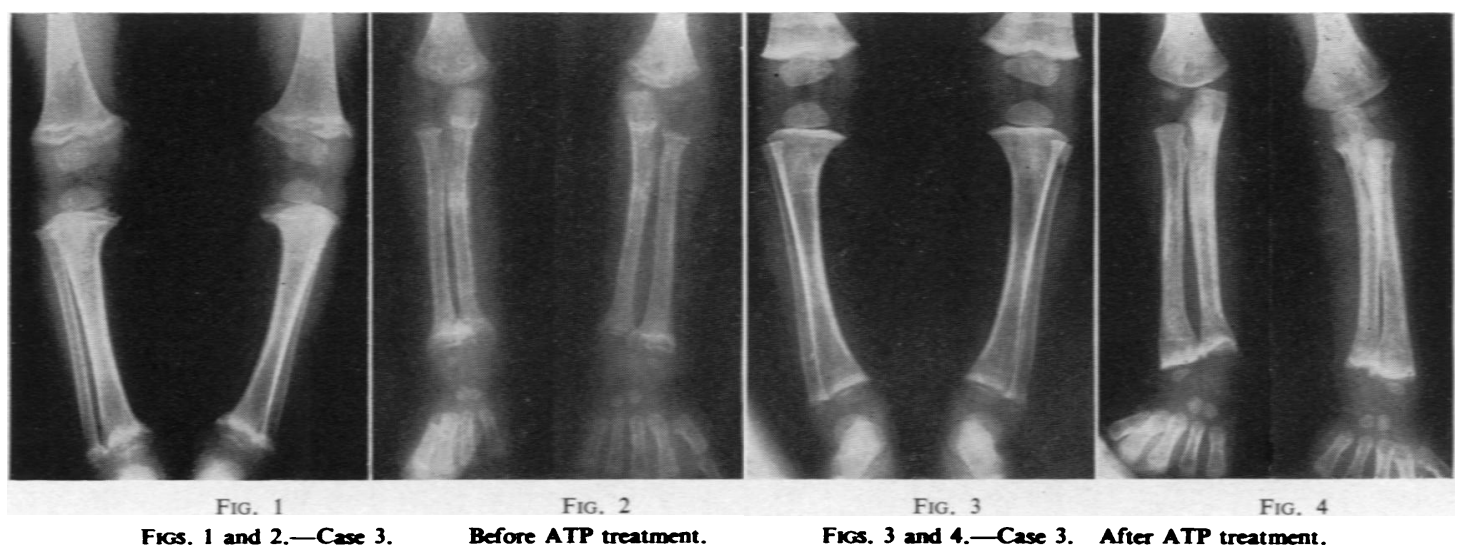


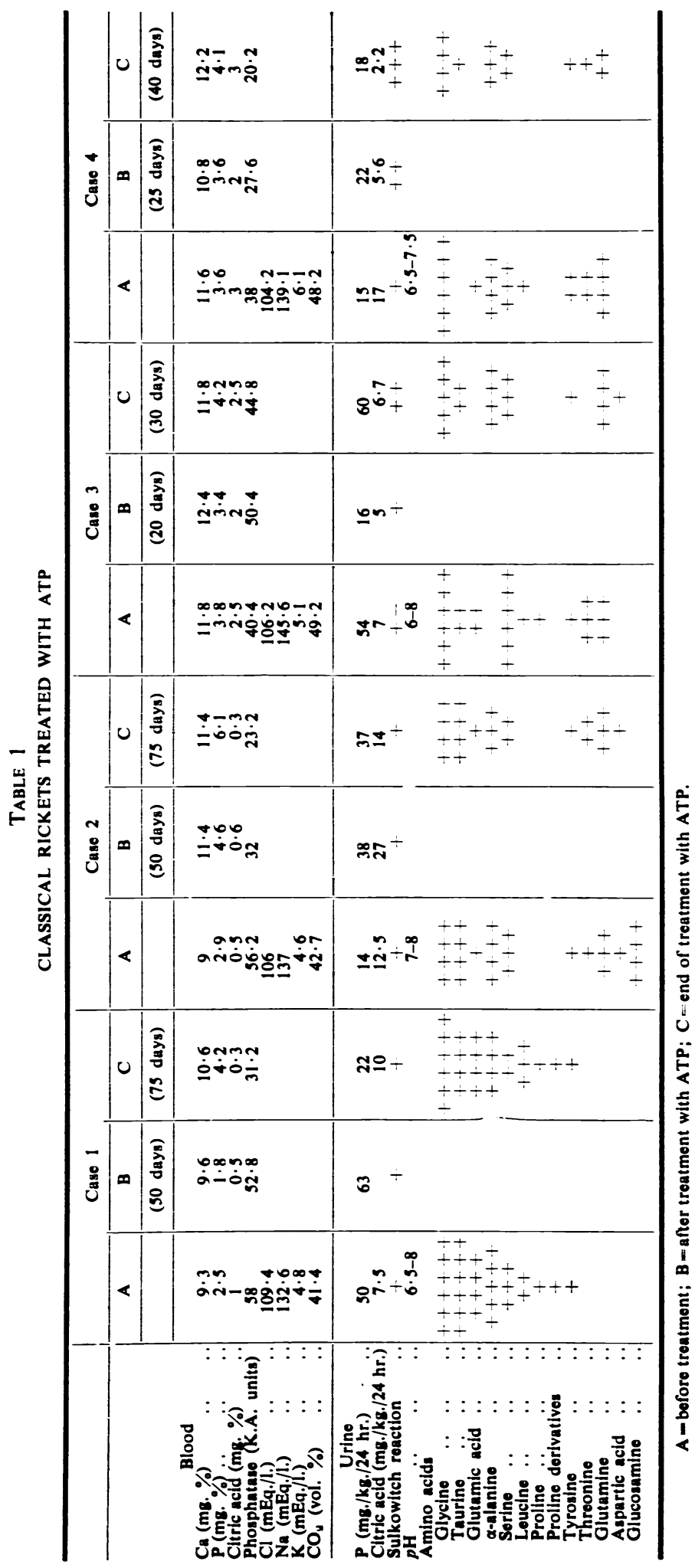


TABLE 2

BIOCHEMICAL FINDINGS

\begin{tabular}{|c|c|c|c|c|c|c|c|c|c|}
\hline & & & & & & Case 5 & & Case 6 & Case 7 \\
\hline & & & & $!$ & A & B & C & $\mathbf{A}$ & $\mathbf{A}$ \\
\hline 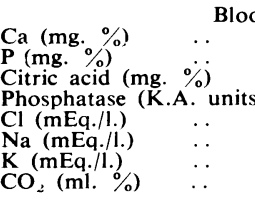 & $\begin{array}{l}\text { od } \\
\cdots \\
\cdots \\
\cdots \\
\cdots \\
\cdots \\
\cdots\end{array}$ & $\begin{array}{l}\cdots \\
\cdots \\
\ldots \\
\cdots \\
\ldots \\
\cdots\end{array}$ & $\begin{array}{l}\ldots \\
\ldots \\
\ldots \\
\ldots \\
\ldots \\
\ldots \\
\ldots\end{array}$ & $\begin{array}{l}\cdots \\
\cdots \\
\cdots \\
\cdots \\
\cdots \\
\cdots \\
\cdots\end{array}$ & $\begin{array}{c}9 \cdot 2 \\
3 \cdot 3 \\
0 \cdot 2 \\
27 \cdot 4 \\
101 \cdot 4 \\
145 \\
5 \\
45\end{array}$ & $\begin{array}{c}10 \cdot 4 \\
7 \\
0 \cdot 35 \\
26 \cdot 8\end{array}$ & $\begin{array}{c}10 \cdot 2 \\
6 \cdot 6 \\
0 \cdot 25 \\
20 \cdot 2\end{array}$ & $\begin{array}{c}9 \cdot 6-11 \cdot 5 \\
3-3 \cdot 5 \\
0 \cdot 15-0 \cdot 2 \\
53 \cdot 2 \\
105 \\
141 \cdot 3 \\
6 \cdot 4 \\
53 \cdot 2\end{array}$ & $\begin{array}{c}9 \cdot 2-9 \cdot 5 \\
3-3 \cdot 6 \\
0 \cdot 15-0 \cdot 25 \\
84 \\
101 \cdot 4 \\
139 \cdot 4 \\
5 \\
47\end{array}$ \\
\hline 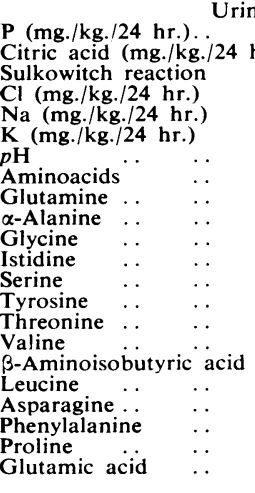 & 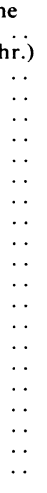 & $\begin{array}{l}\cdots \\
\cdots \\
\cdots \\
\cdots \\
\ldots \\
\cdots \\
\cdots \\
\cdots \\
\cdots \\
\cdots \\
\cdots \\
\cdots \\
\cdots \\
\cdots \\
\cdots \\
\cdots \\
\cdots \\
\cdots\end{array}$ & $\begin{array}{l}\cdots \\
\cdots \\
\cdots \\
\cdots \\
\cdots \\
\cdots \\
\cdots \\
\cdots \\
\cdots \\
\cdots \\
\cdots \\
\cdots \\
\cdots \\
\cdots \\
\cdots \\
\cdots \\
\cdots\end{array}$ & $\begin{array}{l}\cdots \\
\cdots \\
\cdots \\
\cdots \\
\cdots \\
\cdots\end{array}$ & $\begin{array}{l}23 \\
11 \\
\div\end{array}$ & $\begin{array}{c}37 \\
5 \cdot 5 \\
\ldots\end{array}$ & $\begin{array}{r}30 \\
9 \\
+\end{array}$ & $\begin{array}{c}44-56 \\
58-94 \\
+-1 \\
4,170 \\
2,200 \\
85 \\
5-8 \\
\\
++++\ldots \\
+++++ \\
+++++ \\
++++++ \\
+++++ \\
+++ \\
++ \\
++ \\
+\cdots \\
-+\end{array}$ & $\begin{array}{c}38-55 \\
64-75 \\
+ \\
3,300 \\
2,750 \\
150 \\
5-8 \\
+++++ \\
+++++ \\
+++++ \\
++++ \\
+++++ \\
++++ \\
++++ \\
++++ \\
++ \\
+++ \\
++ \\
++ \\
++ \\
+\end{array}$ \\
\hline
\end{tabular}

$\mathbf{A}=$ before treatment $; \mathbf{B}=$ after treatment with Vitamin $\mathbf{D}_{2} ; \mathbf{C}=$ after treatment with $\mathbf{A T P}$

TABLE 3

BLOOD AND URINE CITRIC ACID LEVELS COMPARED WITH THOSE IN NORMAL CONTROLS

\begin{tabular}{|c|c|c|c|c|c|c|c|c|}
\hline & & & & & & Normal Controls & Case 6 & Case 7 \\
\hline Citric acid (mg. \%) in blood & $\cdots$ & $\cdots$ & $\cdots$ & $\cdots$ & $\cdots$ & $1 \cdot 5-5 \cdot 5$ & $0 \cdot 15-0 \cdot 20$ & $0 \cdot 15-0 \cdot 25$ \\
\hline Citric acid (mg./24 hr.) in urine & $\cdots$ & $\cdots$ & $\cdots$ & $\cdots$ & $\cdots$ & $100-600$ & $760-800$ & $550-645$ \\
\hline Citric acid (mg./kg./24 hr.) in urine & $\cdots$ & $\cdots$ & $\cdots$ & $\cdots$ & $\cdots$ & $4-16$ & $89-94$ & $64-75$ \\
\hline Rate $\begin{array}{l}\text { citric acid (mg. \%) in urine } \\
\text { citric acid (mg. \%) in blood }\end{array}$ & $\cdots$ & $\cdots$ & $\cdots$ & $\cdots$ & $\ldots$ & $3-15$ & $660-800$ & $516-733$ \\
\hline
\end{tabular}

TABLE 4

\begin{tabular}{c|ccc}
\hline & Case 6 & Case 7 \\
\hline $\begin{array}{c}\text { Glomerular filtrate } \\
\text { (creatinine) }\end{array}$ & $86 / 1.72 \mathrm{sq} . \mathrm{m} . / \mathrm{min}$. & $85 / 1.72 \mathrm{sq} . \mathrm{m} . / \mathrm{min}$. \\
\hline $\begin{array}{c}\text { Glomerular filtrate } \\
\text { for citric acid } \ldots\end{array}$ & $0.070 / \mathrm{min}$. & $0 \cdot 11 / \mathrm{min}$. \\
\hline $\begin{array}{c}\text { Urinary output citric } \\
\text { acid } \ldots\end{array}$ & $0.84 / \mathrm{min}$ & $0.85 / \mathrm{min}$. \\
\hline
\end{tabular}

(4. $5 \mathrm{mg}$. per $100 \mathrm{ml}$.); the blood citric acid level remained very low $(0.20 \mathrm{mg}$. per $100 \mathrm{ml}$.).

Case 7 received orally over a period of two months 5,000 i.u. of vitamin $\mathrm{D}_{2}$ daily. There was a slight deterioration in the radiological picture, but again the blood phosphorus level became normal (4.5 $\mathrm{mg}$. per
TABLE 5

BIOCHEMICAL FINDINGS IN MOTHER AND SISTER OF CASES 6 AND 7

\begin{tabular}{cc|c|c}
\hline & & $\begin{array}{c}\text { Blood Citric Acid } \\
(\mathrm{mg} . \%)\end{array}$ & Urine Citric Acid \\
\hline Mother &. & 0.20 & $1900 \mathrm{mg} . / 24 \mathrm{hr}$. \\
Sister &. & 0.30 & $(31.6 \mathrm{mg} / \mathrm{kg} . / 24 \mathrm{hr})$. \\
\hline
\end{tabular}

$100 \mathrm{ml}$.$) , and the citric acid level in the blood remained$ very low $(0.30 \mathrm{mg}$. per $100 \mathrm{ml}$.).

Thereafter we started ATP treatment $(5 \mathrm{mg}$. intramuscularly daily over a period of 4 months) in both children. The radiological findings were checked three times during those four months, and a progressive improvement was noted, which culminated in complete 


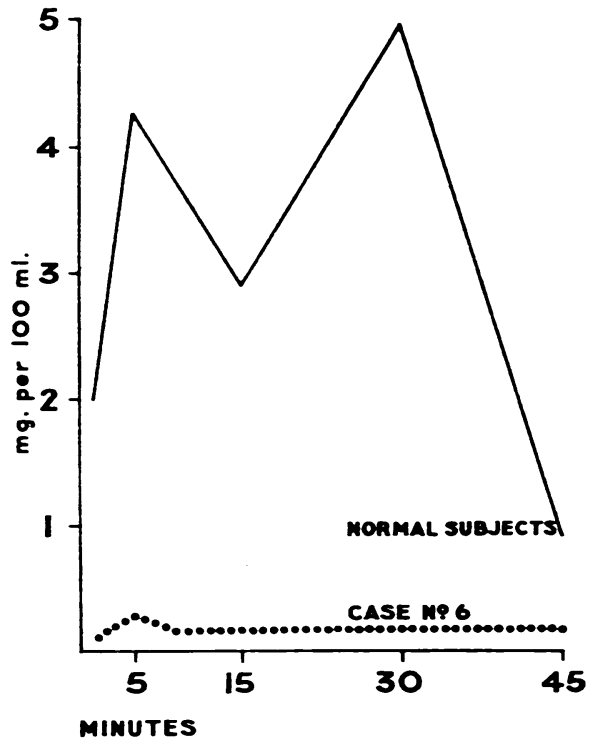

FKG. 5.-Case 6. Blood citric acid levels after intravenous loading with citric acid.

cure at the end of the period of ATP treatment. It was, however, not possible to undertake biochemical follow-up studies.

These cases show (1) a much greater involvement of the citric acid and amino acid levels with lowering of the renal threshold in comparison with the changes in the cakcium and phosphorus levels, and (2) a relative resistance to vitamin $D_{2}$ therapy contrasted with good therapeutic results obtained with ATP.

\section{Review of the Seven Cases}

There is a similarity between Cases 5, 6 and 7 in their poor sensitivity to vitamin $D_{2}$. These are intermediate forms between normal sensitivity and severe resistance to the antirachitic vitamin of Fanconi and Spahr (1956). This resistance shows itself in the first place in the poorness or absence of radiological improvement and in the citric acid levels. On the other hand, the blood phosphorus levels became normal under treatment with vitamin $D_{2}$. This is a different phenomenon from that observed in classical rickets, in which high doses of vitamin $\mathbf{D}_{2}$ frequently lead to an improvement in the radiological findings without improvement in the blood phosphorus level. It may well be that in such cases the correction of the blood phosphorus level proves insufficient, in the presence of changes in citric acid and amino acid metabolism, to ensure normal bone development.

A study of the therapeutic action of ATP in all seven cases confirms the importance of the part played by 'oxidative phosphorylation' (synthesis of ATP in the Krebs cycle) in the pathogenesis of rickets. The lowered renal threshold for citrates and amino acids provides evidence that the changes in 'oxidative phosphorylation' take place predominantly in the renal tubules. The therapeutic action of ATP represents a substitutive effect at the level of the bones, given the fact that the biochemical changes are not uniform in nature. The reduction in phosphatase is a more or less regular feature of an improved skeletal condition. In vitamin D resistant rickets Hoffmann-Credner, Rupp and Swoboda (1955) have demonstrated a deficiency in the synthesis of ATP.

\section{Rickets and Steroid Metabolism}

In Cases 1, 2, 3 and 4 we studied the urinary output of 17-ketosteroids, the Thorn test (with adrenaline) and the blood sugar levels after insulin administration. In three cases the 17-ketosteroid output in the urine showed a rise before onset of treatment (average for that age not higher than $1 \mathrm{mg}$. per day). The drop in eosinophils following administration of adrenaline showed an insufficient reduction in two cases only (Cases 5 and 6). The lowering of blood sugar levels following injection of insulin was not very marked (maximum reduction $25^{\circ}$ ). ATP led to a change in the excretion of 17-ketosteroids and in the results of the Thorn test (Fig. 6).

These findings show that rickets is also associated with disturbances of steroid metabolism. It appears that in the pathogenesis of rickets hyperadrenocorticism plays an important part, representing a contrast to the condition prevailing in idiopathic hypercalcaemia. Future investigations directed towards the total range of suprarenal hormones, especially the 11-oxycorticoids, will lead to further clarification of these problems. It is likely that a disturbance in steroid metabolism may have some bearing on the action of vitamin $D$ and that there exists some relationship between such metabolic disturbance and the sensitivity or resistance of organisms to antirachitic vitamins.

In Case 5 administration of vitamin $\mathrm{D}_{2}$ led to a rise in output of 17-ketosteroids without significant radiological improvement; this may represent an example of the above-mentioned relationship. ATP, apart from effecting a cure of the rachitic condition, has also exerted an influence on that metabolichormonal sphere, probably an action directed towards synthesis of the steroids (ATP-acetylCoAsteroids). 


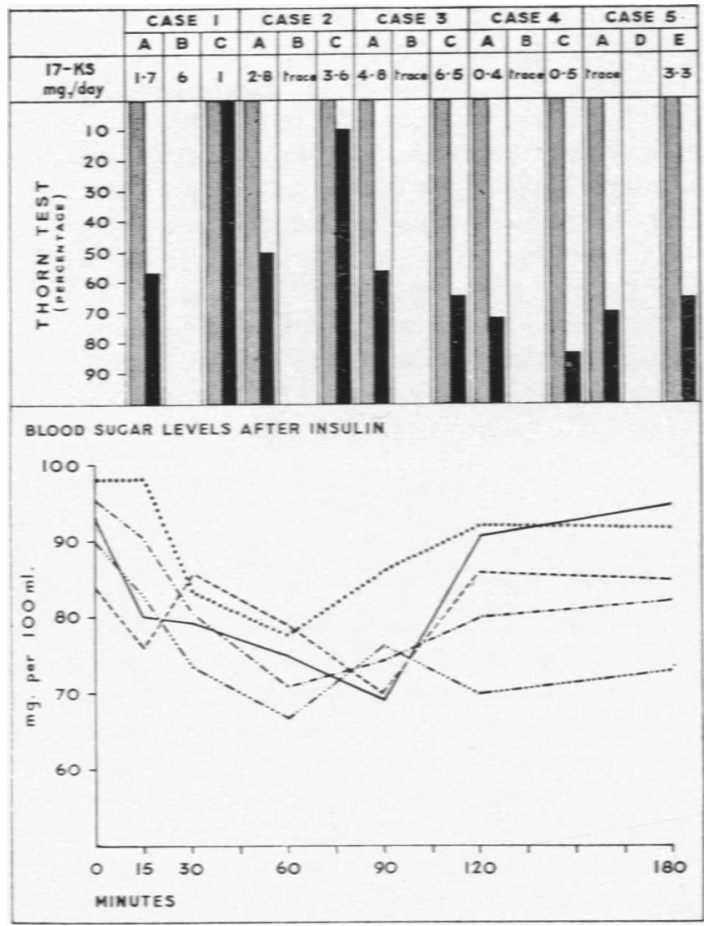

Fig. 6.-Cases 1-5.

$\mathbf{A}=$ before therapy
$\mathbf{B}=$ during ATP therapy

Reanl Rickets with Renal Glaco-phospho-anino Acid Diabetes (de Toni-Debré-Fanconi Symdrome)

Case 8. This was a girl aged 6 years 2 months. At the age of 4 months enlargement of the liver was found, a finding which was confirmed frequently at subsequent examinations. At the age of 8 months a diagnosis of rickets was made and treatment with vitamin $D_{2}$ in massive doses was started (Ostelin-800). At the age of 2 years glycosuria was detected for the first time. From the age of 4 years the patient complained of pains in the bones and joints and of difficulty in walking. From that time on she was subjected, without any satisfactory results, to various therapeutic procedures, the details of which were not given. The statural development was normal for her age ("pachysomia" according to de Toni's classification). There were severe clinical and radiological signs of rickets with a tendency to recurrences, especially in the long bones, and enlargement of the liver and spleen. Plain radiological examination as well as radiographs taken after insuffiation of air into the retroperitoneal space showed enlargement of both kidney shadows. Results of blood and urine examinations are given in Table 6.

After treatment with ATP (10 mg. per day over a period of two months) we found that the glycosuria, phosphaturia and aminoaciduria were practically unchanged (Table 7), and there was no change on radiological examination of the skeleton.

In the course of a determination of the endogenous creatinine glomerular filtrate before therapy we were able to establish the clearance values for citric acid and phosphorus shown in Table 8.

Such results demonstrate that the tubular reabsorption of phosphorus corresponds to $92 \cdot 7 \%$ of the glomerular filtrate. The glomerular filtrate per minute of citric acid was smaller than the urinary flow per minute. It is possible that the renal tubule secretes $0.29 \mathrm{mg}$. citric acid per minute.

Case 8 is a case of 'renal rickets with renal glucophospho-amino acid diabetes' without dwarfism and with enlargement of the kidneys. There are no reports in the literature of cases of de Toni-DebréFanconi syndrome without dwarfism and with nephromegaly. The case is difficult to interpret with regard to the enlarged kidneys. The blood sugar curve following injection of adrenaline and loading with glucose does not suggest any hepatorenal glycogen storage disease. The spleen contracted following adrenaline injection. Apart from glucose, the urine contained pentose, as in the case of Aballi, Montero, Escobar Acés and Jimenez (1944); it also contained in larger or smaller quantities all the amino acids which are commonly found in the de Toni-Debré-Fanconi syndrome. The output of urinary phosphatase was increased. The Ellsworth-Howard test was negative (Fig. 7), showing that the tubular reabsorption of phosphorus was impaired to such a degree that no subsequent modification could take place. There was only a slight change in the acidification of the urine without true acidosis and with a slight increase in the blood chlorides. The polyuria, which was not marked, responded to pitressin administration (Fig. 8). We were unable to do a liver biopsy, but the liver function tests failed to reveal the presence of a cirrhotic condition such as that found by Dent (1947) in other cases of the syndrome.

The citric acid levels were very low in the blood and high in the urine. The glomerular filtrate of citric acid was lower than the urinary flow. In this particular case the 'gluco-phospho-amino acid renal diabetes' proved to be associated with 'citric acid renal diabetes'. An increase in organic acids (ketobodies, pyruvic acid, uric acid) was found in cases of 'de Toni-Debré-Fanconi syndrome' by Aballi et al. (1944), van Creveld and Arons (1949) and Sirota and Hamerman (1954).

Our findings show that a disturbance of the 'Krebs cycle' occurs in the renal tubules in some cases of 'de Toni-Debré-Fanconi syndrome'. Nordio 
TABLE 6

BLOOD AND URINE ANALYSIS IN CASE 8

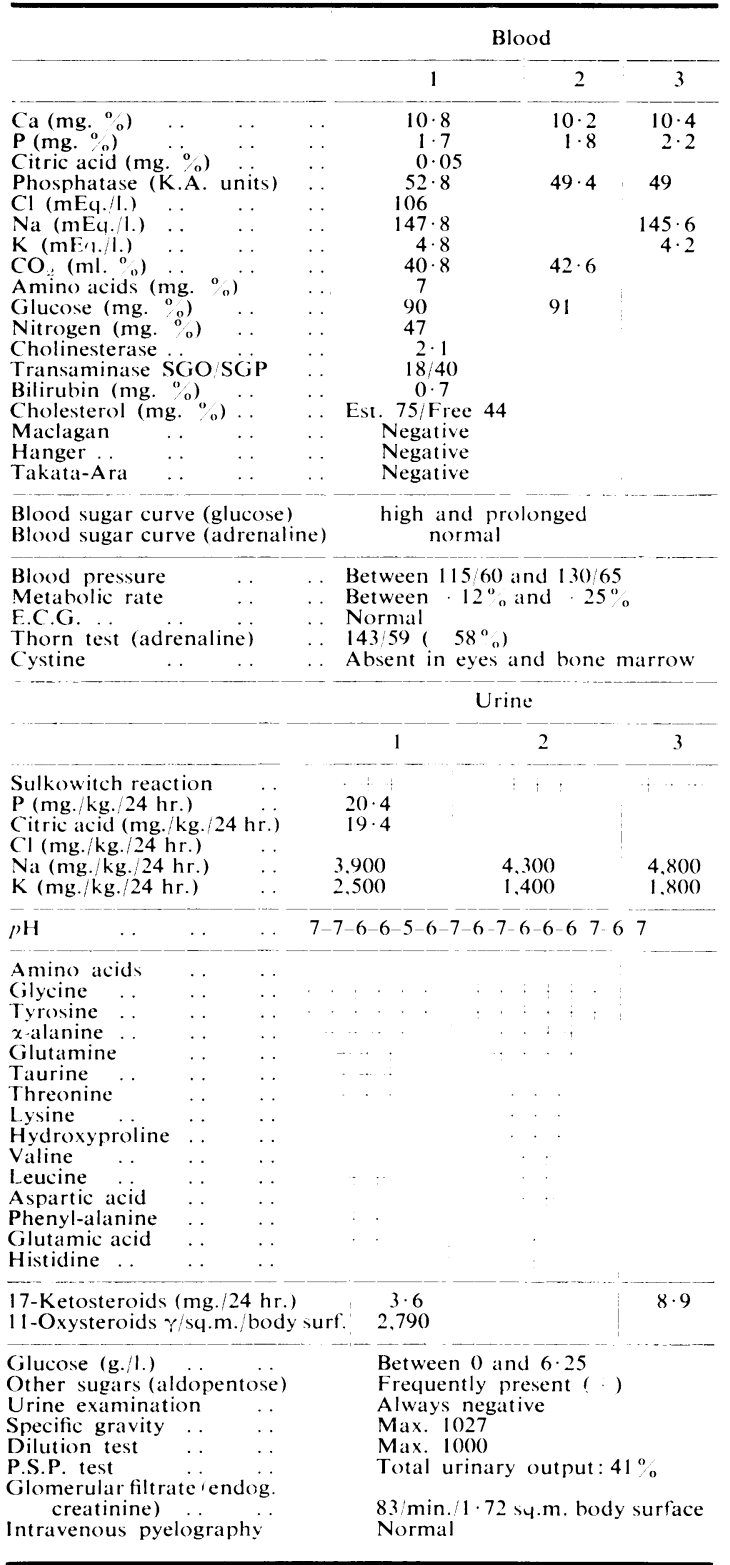

et al. (1956) have produced experimentally in rabbits a 'de Toni-Debré-Fanconi syndrome' by means of the administration of succinates (metabolites originating in the 'Krebs cycle'). In animals subjected to this treatment they found swelling of the mitochondria in the cells of the renal tubules, indicating a probable uncoupling of the oxidative phosphoryla-
TABLE 7

BLOOD ANALYSIS IN CASE 8 AFTER TWO MONTHS TREATMENT WITH ATP

\begin{tabular}{|c|c|c|}
\hline $\begin{array}{l}\text { Citric } \\
\text { Calciu } \\
\text { Phosp } \\
\text { Phosp }\end{array}$ & $\begin{array}{l}\operatorname{acid}(\mathrm{mg} . \%) \\
\mathrm{m}(\mathrm{mg} .0 \\
\text { horus }(\mathrm{mg}) \% \text { or. }\end{array}$ & $\begin{array}{l}0 \cdot 5 \\
11 \cdot 8 \\
2 \\
34 \cdot 8\end{array}$ \\
\hline \multicolumn{3}{|c|}{$\begin{array}{l}\text { TABLE } 8 \\
\text { CASE } 8\end{array}$} \\
\hline \multicolumn{2}{|r|}{ Glomerular Filtrate/min. } & Urinary Output $/ \mathrm{min}$. \\
\hline $\begin{array}{l}\text { Citric acid } \\
\text { Phosphorus }\end{array}$ & $\begin{array}{l}0 \cdot 16 \\
2 \cdot 2\end{array}$ & $\begin{array}{l}0 \cdot 31 \\
0 \cdot 23\end{array}$ \\
\hline
\end{tabular}

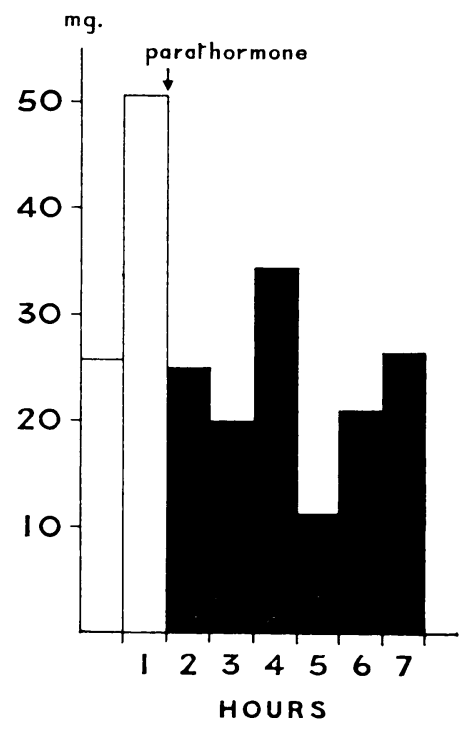

Fig. 7.-Case 8. Ellsworth-Howard test showing tubular parathormone resistance.

tion process. The hypothesis was suggested, and supported also by Freudenberg (1954), that the synthesis of ATP had undergone some disturbance. Schwarz-Tiene, Careddu and Cabassa (1957) showed the existence of an analogous condition in cases of 'de Toni-Debré-Fanconi syndrome' produced experimentally by means of the administration of cystine. Harrison (1954) and subsequently Durand et al. (1956) produced an experimental 'de Toni-Debré-Fanconi syndrome' by administration of maleic acid (an antimetabolite of malic acid, the tricarboxylic acid of the 'Krebs cycle'). Durand et al. (1956) also noted, in animals treated in this way, a disappearance of the glycosuria following administration of ATP.

For these reasons we treated a rabbit with alpha- 


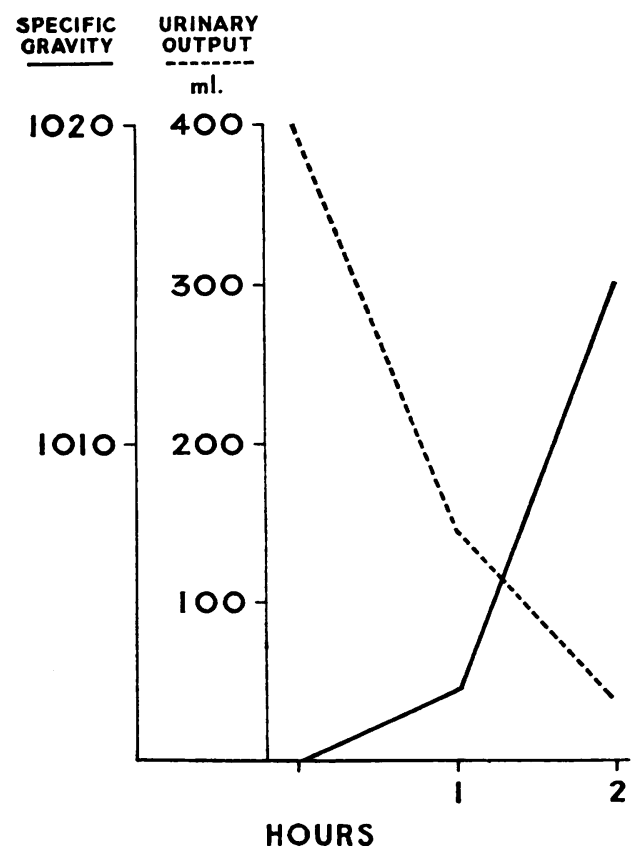

Fig. 8.-Case 8. Pitressin test showing a tubular pitressin sensitivity.

dinitrophenol (DNP), which leads to an uncoupling of oxidative phosphorylation; however, we did not succeed in producing a 'de Toni-Debré-Fanconi syndrome' (Table 9). After treatment there was some osteofibrosis in the juxtametaphyseal region similar to that observed by Nordio et al. (1956) after treatment of the rabbit with succinates.

As regards the relationship between the 'de ToniDebré-Fanconi syndrome' and the 'uncoupling of oxidative phosphorylation', we must draw attention to the fact that, in contrast with the other cases of rickets which we have investigated, ATP had no therapeutic effect in our case, apart from a moderate increase in the citric acid and phosphorus levels of the blood and a drop in the phosphatase levels. The patient was subjected to combined treatment with ATP and vitamin $\mathrm{D}_{2}$.

The increased urinary output of 17-ketosteroids and of 11-oxysteroids, which we observed in our case, shows that there exists in the 'de Toni-DebréFanconi syndrome' an additional disturbance in steroid metabolism. The latter may be associated with the metabolic disturbance of the 'Krebs cycle'.

\section{Tetany with Hyperadrenocorticism and (?) Hypopara- thyroidism}

Case 9. This girl was 13 months old. From the age of 6 months she had been subjected to continuous treat- ment with vitamin $D_{2}$. She was admitted to our clinic with signs of tetany and radiological examination failed to show any evidence of rickets or of osteosclerosis (Figs. 9 and 10).

Treatment consisted of 20 i.u. of parathormone daily for five days, 20,000 i.u. of vitamin $D_{2}$ daily for five days and $\mathrm{AT}_{10}$ (Calcamina Wander $0.5 \%$ oily solution) 10 to 60 drops daily over a period of 50 days (combined with $20 \mathrm{mg}$. of prednisolone daily over a period of eight days). After an interruption of one month, during which calcium was administered, treatment with $\mathrm{AT}_{10}, 15$ drops daily, was resumed and continued without interruption during the whole course.

This was a case of tetany with hypocalcaemia, hyperphosphataemia and lowered blood phosphatase (Table 10). Renal function was normal, there was no intestinal stasis and no radiological evidence of rickets. The low blood citric acid and urinary citric acid levels correspond to the findings in other forms of tetany with hypocalcaemia. These findings are characteristic of a certain form of 'hypoparathyroidism'. The results of the Howard test showed a drop in urinary phosphate excretion, which was already low before the test, indicating that the parathyroid function, which was depressed before the test, was susceptible to further depression as a result of the intravenous infusion of calcium (Fig. 11). In view of the difficulty in taking blood samples every hour, determinations were made only in the urine.

The patient's response to the various forms of treatment was abnormal, a relative resistance to $\mathrm{AT}_{10}$ developing during a certain period.

Of special importance are the results of the studies of suprarenal function which showed an all-round increase. Radiological examination after insufflation of air into the retroperitoneal space revealed no enlargement of the suprarenals (Fig. 12). The presence of hyperaldosteronism was confirmed by the rather high urinary output of potassium (Fig. 13) and by the occurrence of hypopotassaemic crises

TABLE 9

BLOOD AND URINE ANALYSIS IN A RABBIT FOLLOWING TREATMENT WITH DNP

\begin{tabular}{|c|c|c|c|}
\hline & $\begin{array}{c}\text { Before } \\
\text { Treatment }\end{array}$ & After 4 Days & After 10 Days \\
\hline \multicolumn{4}{|l|}{ Blood } \\
\hline \begin{tabular}{ll|}
$\mathrm{CO}_{2}$ (ml. \%) & $\cdots$ \\
$\mathbf{P}(\mathrm{mg} . \%)$ & $\cdots$ \\
$\mathbf{K}(\mathrm{mg} . \%)$ & $\cdots$ \\
Glucose (mg. $\%$ )
\end{tabular} & $\begin{array}{c}55 \cdot 2 \\
2 \cdot 6 \\
16 \\
111\end{array}$ & $\begin{array}{l}58 \cdot 7 \\
1 \cdot 6 \\
17 \\
130\end{array}$ & $\begin{array}{c}47 \cdot 6 \\
2 \cdot 9 \\
24 \\
148\end{array}$ \\
\hline \multicolumn{4}{|l|}{ Urine } \\
\hline $\begin{array}{ll}\mathrm{CO}_{2}(\mathrm{ml} . \%) & \ldots \\
\mathbf{P}(\mathrm{mg} \% & \% \\
\text { Fehling test } & . . \\
\text { Aminoaciduria } & \ldots\end{array}$ & $\begin{array}{c}149 \\
6 \cdot 2 \\
\text { Negative } \\
\text { Normal }\end{array}$ & $\begin{array}{l}800 \\
7 \cdot 5 \\
\text { Negative } \\
\text { Normal }\end{array}$ & $\begin{array}{l}31 \cdot 4 \\
10 \\
\text { Negative } \\
\text { Normal }\end{array}$ \\
\hline
\end{tabular}



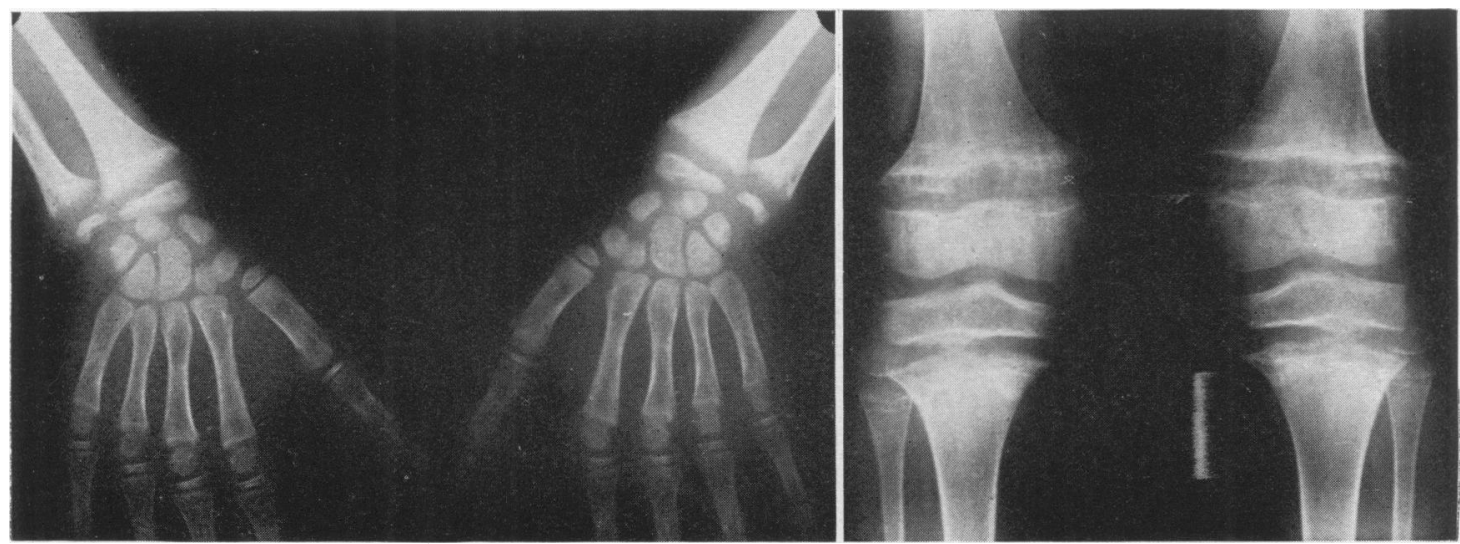

FIGs. 9 and 10.-Case 9.

TABLE 10 BIOCHEMICAL FINDINGS IN CASE 9

\begin{tabular}{|c|c|c|c|c|c|}
\hline \multicolumn{5}{|c|}{ Blood } & \multirow[b]{2}{*}{$\begin{array}{l}7 \cdot 2-8 \\
8-11 \\
0 \cdot 5 \\
2 \cdot 2 \\
145 \cdot 6 \\
102 \cdot 8 \\
4 \cdot 7 \\
59 \cdot 3\end{array}$} \\
\hline 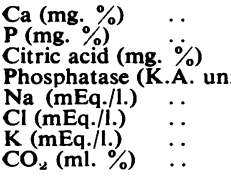 & $\begin{array}{l}\cdots \\
\cdots \\
i \operatorname{its)} \\
\cdots \\
\cdots \\
\cdots\end{array}$ & $\begin{array}{l}\cdots \\
\cdots \\
\cdots \\
\cdots \\
\cdots\end{array}$ & $\begin{array}{l}\cdots \\
\cdots \\
\cdots \\
\cdots \\
\cdots \\
\cdots\end{array}$ & \begin{tabular}{l|}
$\cdots$ \\
$\cdots$ \\
$\cdots$ \\
$\cdots$ \\
$\cdots$ \\
$\cdots$ \\
$\cdots$
\end{tabular} & \\
\hline \multicolumn{5}{|c|}{ Urine } & \\
\hline 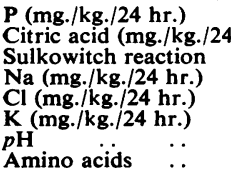 & $\begin{array}{l}\text { hr.) } \\
\ldots \\
\ldots \\
\ldots \\
\ldots \\
\ldots \\
\ldots\end{array}$ & $\begin{array}{l}\cdots \\
\cdots \\
\cdots \\
\cdots \\
\cdots \\
\cdots\end{array}$ & $\begin{array}{l}\cdots \\
\cdots \\
\cdots \\
\cdots \\
\cdots \\
\cdots\end{array}$ & \begin{tabular}{l|}
$\cdots$ \\
$\cdots$ \\
$\cdots$ \\
$\cdots$ \\
$\cdots$ \\
$\cdots$ \\
$\cdots$
\end{tabular} & $\begin{array}{c}3 \cdot 1-1 \cdot 7 \\
4 \cdot 9 \\
\text { Between }+ \text { and }++ \\
125 \\
225 \\
124 \\
\text { Between } 5 \text { and } 7 \\
\text { Normal }\end{array}$ \\
\hline
\end{tabular}

Renal functions (blood nitrogen, urine examination, concentration test, P.S.P. test)

Neuromuscular hyperexcitability ...

E.C.G. Phonocardiogram: Typical for hypocalcaemia with increased mechanical systole

Galvanic stimulation (Erb's sign): Typical of hypocalcaemia

Thorn test (adrenaline)

.. $\quad$. $50-0 \cdot 3(-150 \%)$

$\begin{array}{lllllll}\text { Aldosterone }(\gamma / 24 / \mathrm{hr}) & & \end{array}$

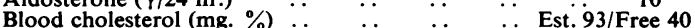

Cultures for Candidae (stools, urine, pharynx) ..

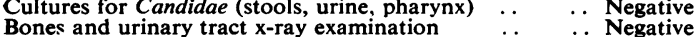

Bones and urinary tract x-ray examination
Ophthalmological examination (lens and fundus)

.. Negative

E.E.G. examination

.. Negative

during treatment with $\mathrm{AT}_{10}$. It seems likely that the hypopotassaemia was associated with a state of alkalosis (for technical reasons it was impossible to determine the $\mathrm{CO}_{2}$ levels in the blood plasma), for in a subsequent case the levels of $\mathrm{CO}_{2}$ in the blood plasma proved to be rather high following a return to normal of the blood potassium levels.

Interpretation of this case is difficult. The hyperadrenocorticism might account for the hypocalcaemia but not for the hyperphosphataemia. In

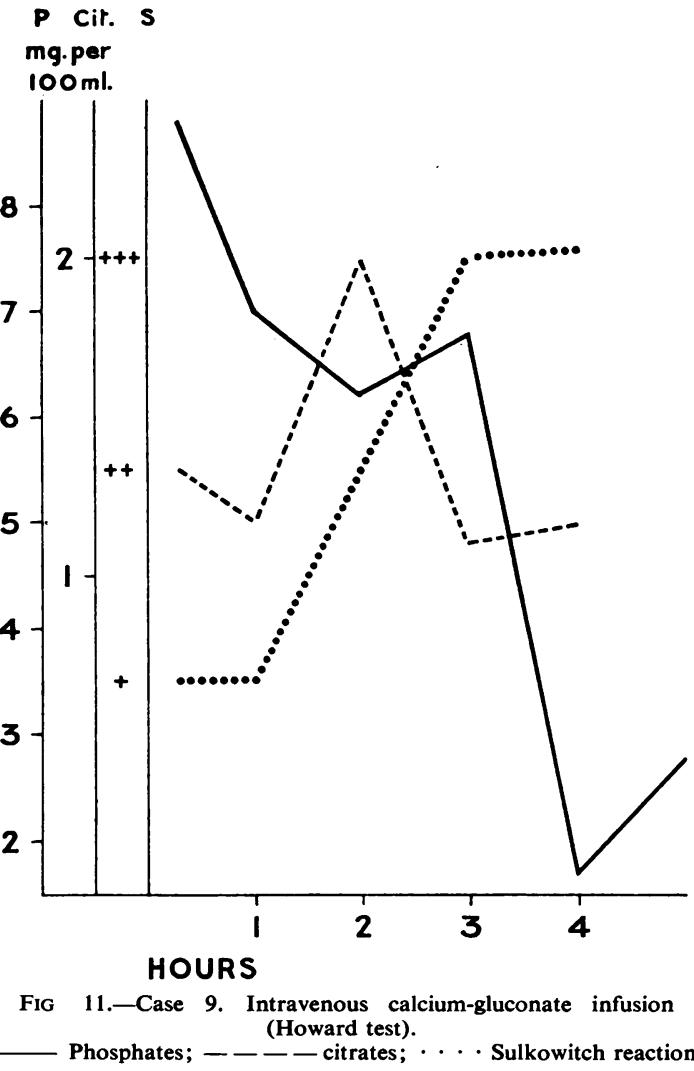

the absence of renal disturbances one suspects 'hypoparathyroidism associated with hyperadrenocorticism'. It may therefore be a case of two different endocrine disturbances both exerting a negative influence on the calcium balance of the organism. 


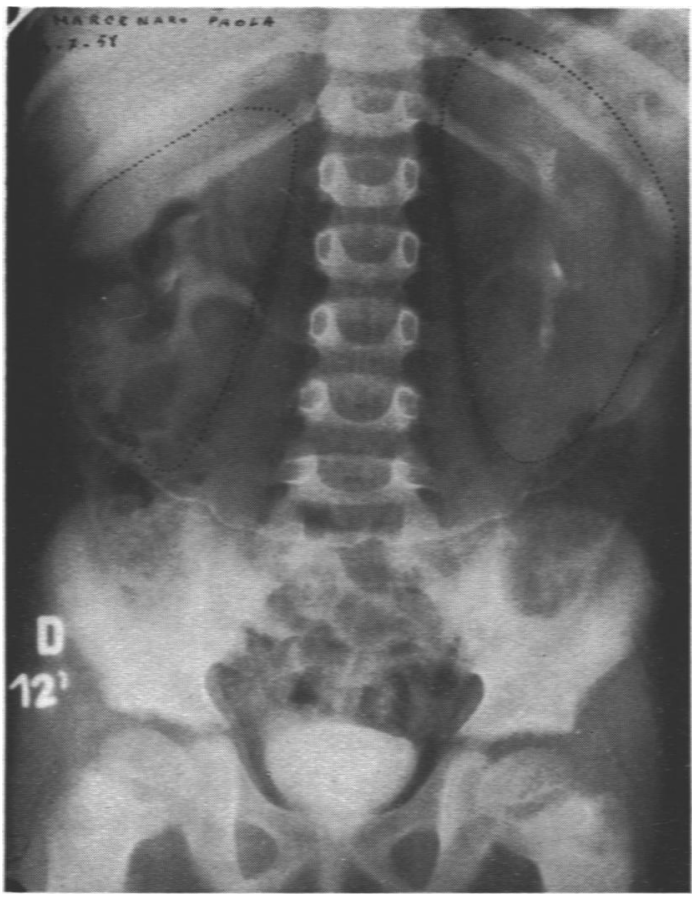

Fig. 12.-Case 9.

A functional relationship between the parathyroid and suprarenal glands is demonstrated in these cases by a return to normal of the 17-ketosteroids output during treatment with parathormone (Fig. 14). The changes in 17-ketosteroid excretion after treatment with vitamin $D_{2}$ and $A T_{10}$ provide further evidence of a complete change in the steroid balance.

\section{Rachitogenous Tetainy}

Case 10. A girl, aged 10 months, was admitted to our clinic following an attack of tonic and clonic convulsions. All clinical signs of tetany were positive. Erb's test as well as an electrocardiogram were characteristic of hypocalcaemia. Radiological examination showed evidence of fresh rickets. There was evidence of a disturbance in citric acid metabolism in tetany caused by rickets.

In view of the fact that there was no decrease in citric acid excretion in the urine, and especially in view of the low citric acid levels in the blood (Table 11), it is possible that in this case also there was a lowering of the renal threshold. In contrast to the other case of tetany (Case 9) and to some cases of classical rickets, the urinary output of 17-ketosteroids proved to be normal. On the other hand, the Thorn test suggested an impaired function of the pituitary and suprarenals.

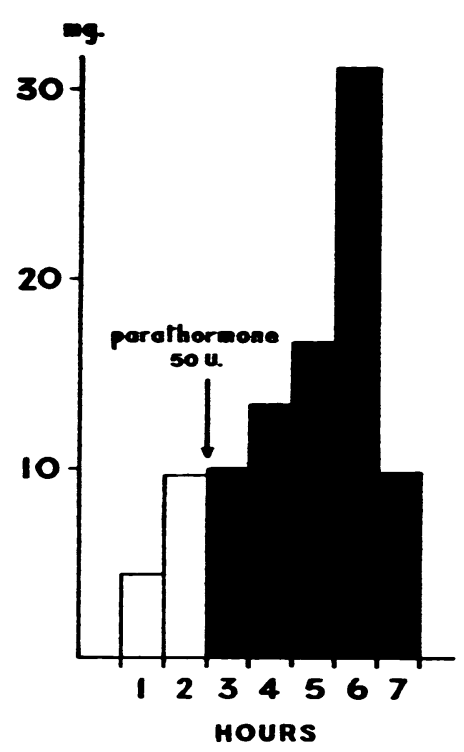

Fig. 13.-Case 9. Elkworth-Howard test showing increased $\mathbf{P}$ output in urine.

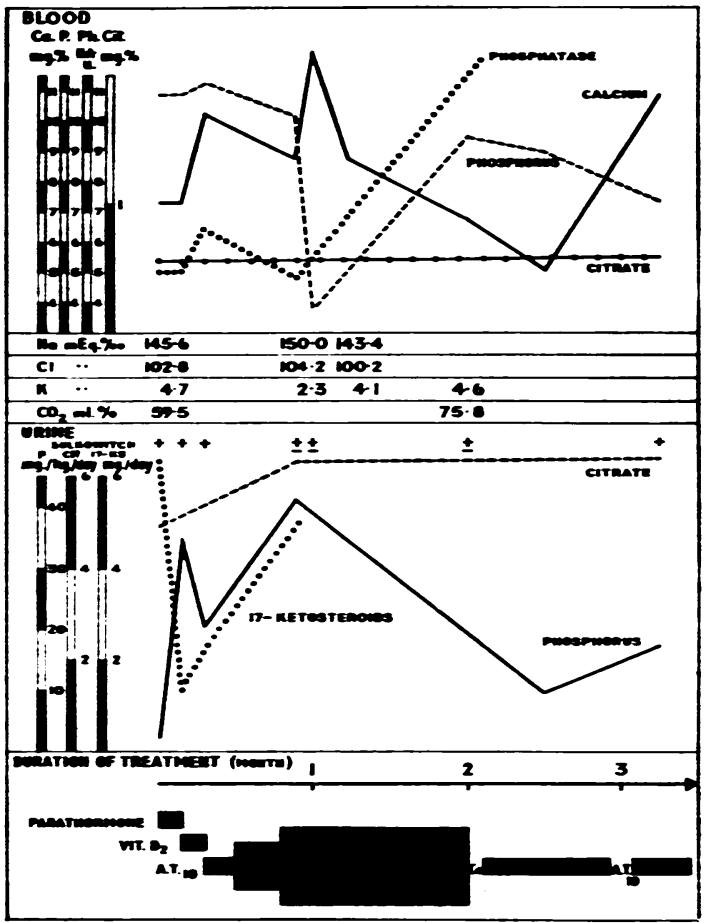

Fic. 14.-Case 9. Biochemical findings during treatment. 
TABLE 11

BIOCHEMICAL FINDINGS IN CASE 10

\begin{tabular}{|c|c|c|c|c|c|c|}
\hline \multicolumn{6}{|c|}{ Blood } & \multirow[b]{2}{*}{$\begin{array}{c}5 \cdot 2 \\
3 \cdot 2 \\
0 \cdot 3 \\
30 \\
136 \cdot 4 \\
103 \cdot 4 \\
5 \cdot 3\end{array}$} \\
\hline $\begin{array}{l}\text { Ca (mg. \%) .. } \\
\text { P (mg. \%) .. } \\
\text { Citric acid (mg. \%) } \\
\text { Phosphatase (K.A. } \\
\text { Na (mEq./1.) . } \\
\text { Cl (mEq./1.) } \quad . \\
\text { K (mEq./l.) } \quad .\end{array}$ & $\begin{array}{l}\ldots \\
\ldots \\
\text { units) } \\
\ldots \\
\ldots \\
\ldots\end{array}$ & $\begin{array}{l}\cdots \\
\cdots \\
\cdots \\
\cdots \\
\cdots\end{array}$ & $\begin{array}{l}\cdots \\
\cdots \\
\cdots \\
\cdots\end{array}$ & $\begin{array}{l}\cdots \\
\cdots \\
\cdots \\
\cdots \\
\cdots\end{array}$ & $\begin{array}{l}\cdots \\
\cdots \\
\cdots \\
\cdots \\
\cdots\end{array}$ & \\
\hline \multicolumn{6}{|c|}{ Urine } & \\
\hline $\begin{array}{l}\text { P (mg. } / \mathbf{k g} . / 24 \mathrm{hr} .) \\
\text { Citric acid (mg./kg./ } \\
\mathrm{Na}(\mathrm{mg} . / \mathrm{kg} . / 24 \mathrm{hr} .) \\
\mathrm{K}(\mathrm{mg} . / \mathrm{kg} . / 24 \mathrm{hr} .) \\
\mathrm{Cl}(\mathrm{mg} / \mathrm{kg} . / 24 \mathrm{hr} .) \\
\text { Sulkowitch reaction } \\
\text { pH } \\
\text { Thorn test .. } \\
\text { 17-Ketosteroids }\end{array}$ & $\begin{array}{l}2 \ddot{24} \text { hr.) } \\
\ldots \\
\ldots \\
\ldots \\
\ldots \\
\ldots \\
\ldots\end{array}$ & $\begin{array}{l}\cdots \\
\cdots \\
\cdots \\
\cdots \\
\cdots \\
\cdots \\
\cdots\end{array}$ & $\begin{array}{l}\ldots \\
\cdots \\
\cdots \\
\cdots \\
\cdots \\
\cdots\end{array}$ & $\begin{array}{l}\cdots \\
\cdots \\
\cdots \\
\cdots \\
\cdots \\
\cdots\end{array}$ & \begin{tabular}{l|}
$\cdots$ \\
$\cdots$ \\
$\cdots$ \\
$\cdots$ \\
$\cdots$ \\
$\cdots$ \\
$\cdots$
\end{tabular} & $\begin{array}{c}50 \\
12 \\
75 \\
17 \\
125 \\
+ \\
\text { Between } 5 \text { and } 6 \\
\text { 46-13 }(-25 \%) \\
\text { Trace }\end{array}$ \\
\hline
\end{tabular}

\section{Discussion}

The cases reported show clearly that isolated investigation of data relating to calcium, phosphorus and phosphatase do not provide a comprehensive picture of the pathogenesis of disturbances of calcium-phosphorus metabolism and ossification. Cases 5, 6 and 7 also provide evidence that the radiological picture of the skeleton does not necessarily run parallel to the blood calcium and phosphorus levels.

We have confirmed the importance in pathogenesis of the metabolism of citrates as well as of their renal threshold not only in classical rickets but also in cases of tetany associated with rickets, in cases of vitamin D resistant rickets, in the 'de Toni-Debré-Fanconi syndrome' and in a special form of 'hyperadrenocorticism-hypoparathyroidism'. The changes in citric acid metabolism and the therapeutic action of ATP indicate that disturbances affecting the process of 'oxidative phosphorylation' can play an important part in the pathogenesis of rickets. Such a concept finds confirmation in the therapeutic action exerted by Pantetine in classical rickets (Coenzyme A) (Nordio et al., 1957). Some disturbance of 'oxidative phosphorylation' occurs also in the 'de ToniDebré-Fanconi syndrome'. The absence or weakness of any therapeutic action of ATP in a case of that disease and the fact that it has not been possible to produce the condition experimentally by administration of DNP show clearly that certain differences, not yet accurately defined, exist between the biochemical disturbance underlying classical rickets and that leading to vitamin $\mathrm{D}$ resistant rickets or the de Toni-Debré-Fanconi syndrome. The increased urinary output of steroids in some cases of rickets and in the "de Toni-Debré-Fanconi syndrome' may be due to a disturbance of the whole steroid metabolism, as in idiopathic hypercalcaemia. There is probably a very close relationship between the disturbances of citric acid metabolism on the one hand and steroids on the other.

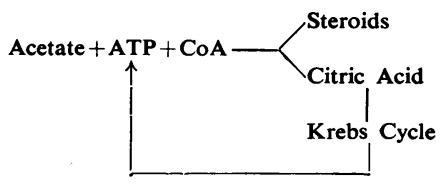

Evidence of such connexions can be found in a case in which an endocrine disturbance, probably caused by a suprarenal tumour, was associated with changes in the blood and urine levels of citric acid. This was in a boy, aged 3, who showed clear evidence of precocious puberty of adrenal type (enlarged penis, pubic and axillary hair, and testicles of normal size). Radiological examination following insufflation of air into the retroperitoneal space showed an enlargement of the right suprarenal gland with some calcification. Before we were able to complete all necessary investigations and to submit the boy to laparotomy the parents decided to take him home (Table 12). In Case 9 we believe that a more

TABLE 12

BIOCHEMICAL FINDINGS IN A CASE OF PRECOCIOUS PUBERTY OF ADRENAL TYPE

\begin{tabular}{|c|c|c|c|c|c|c|}
\hline \multicolumn{6}{|c|}{ 17-Ketosteroids (mg./24 hr.) } & \multirow{2}{*}{$\begin{array}{c}7 \cdot 86-11 \cdot 3 \\
1124 \\
1800 \\
1200 \\
1800 \\
1500\end{array}$} \\
\hline $\begin{array}{c}\text { Chromatography o } \\
\text { Fraction I } \\
\text { Fraction II-III } \\
\text { Fraction IV-V } \\
\text { Fraction VI-VII } \\
\text { Fraction VIII }\end{array}$ & $\begin{array}{l}\text { he } \\
\cdots \\
\cdots \\
\cdots \\
\cdots \\
\cdots\end{array}$ & $\begin{array}{l}\text { oids } \\
\cdots \\
\cdots \\
\ldots \\
\cdots \\
\cdots\end{array}$ & $\begin{array}{l}\cdots \\
\cdots \\
\cdots \\
\cdots \\
\cdots\end{array}$ & $\begin{array}{l}\ldots \\
\cdots \\
\cdots \\
\cdots\end{array}$ & $\begin{array}{l}\cdots \\
\cdots \\
\cdots \\
\cdots \\
\cdots\end{array}$ & \\
\hline \multicolumn{4}{|c|}{$\begin{array}{l}\text { Citric acid in blood (mg. per } 100 \mathrm{ml} .) \\
\text { Citric acid in urine (mg./ kg. } / 24 \mathrm{hr} \text {.) }\end{array}$} & 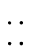 & & $\begin{array}{l}0 \cdot 5 \\
3\end{array}$ \\
\hline
\end{tabular}

detailed study of the relationship between the parathyroid and suprarenal glands would be of considerable interest.

\section{Conclusions}

We consider that, for an elucidation of the disturbances of calcium and phosphorus metabolism and of ossification, the function of the "citric acid cycle', which is closely correlated with the action of the parathyroid hormone, and that of vitamin D and $\mathrm{AT}_{10}$, is of considerable importance (Harrison and Harrison, 1952a; Nordio et al., 1956). It is likely that the sensitivity and resistance of the organism to vitamin $\mathrm{D}$ and $\mathrm{AT}_{10}$ are closely related to steroid metabolism and the 'Krebs cycle' in the renal tubules. Special importance is attached to the 
function of the 'Krebs cycle' in the renal tubules. It controls the reabsorption of amino acids, glucose and phosphorus and regulates the acid-base equilibrium, as shown in the studies of Cooke, Segar, Darrow, Reed, Etzwiler, Brusilow and Vita (1953), Harrison (1954), Durand et al. (1956) and Nordio et al. (1956) and in the investigations carried out in our case of 'de Toni-Debré-Fanconi syndrome'. In view of certain biochemical disturbances common to these pathological conditions, some relationship may also exist between the 'de Toni-Debré-Fanconi syndrome', classical rickets and vitamin D resistant rickets. In some cases of rickets it was also possible to demonstrate the presence of hyperphosphaturia, hyperaminoaciduria, renal acidosis and eventually glycosuria (Jonxis, 1955; Jeune, Charrat, Cotte and Freycon, 1958; Bickel, 1958), and a fall in blood citric acid levels with hypo- or hypercitruria.

The changes affecting the 'Krebs cycle' may be related to similar disturbances of steroid metabolism found in some types of rickets, in our case of 'de ToniDebré-Fanconi syndrome' and in that of hypoparathyroidism. These observations suggest the possibility of a unified pathogenesis for this varied group of pathological conditions.

\section{Methods Used}

Citric acid: Pucher-Sherman-Vickery modified by Bonsignore and Ricci

Sodium and potassium: flame photometry

Calcium: precipitation according to Powell and estimation by flame photometry

Phosphorus: Gomory

Alkali reserve: van Slyke

Alkaline phosphatase: King-Armstrong

Creatinine: Folin-Wu

Blood sugar: Hagedorn-Jensen

Blood amino acids: Böhm-Grüner

Bilirubin: Jendrassik-Grof

17-Ketosteroids in urine: acid hydrolysis and extraction according to Pincus and Balter; colorimetric estimation according to Zimmerman modified by Callow

11-Oxysteroids: Gornall and McDonald

Aldosterones: Neher-Wettstein

Transaminase: Thonhazy-White-Umbreit

Cholinesterase: Hall-Lucas

\section{Summary}

A new approach to the mechanism regulating calcium/phosphorus metabolism and the process of ossification has been suggested. In classical and vitamin D resistant rickets as well as in the 'de ToniDebré-Fanconi syndrome' evidence has been found of a disturbance of citric acid metabolism and of the suprarenal steroids; the same disturbances have been shown in a case of tetany with hyperadrenocorticism: such biochemical disturbances are probably related to one another. It seems possible that an alteration in the 'Krebs cycle' operating in the renal tubules plays an important part. In one case of 'de Toni-Debré-Fanconi syndrome' and in two cases of rickets, which did not respond to the usual treatment with vitamin $D_{2}$, the renal threshold for citric acid was lowered ('renal citrate diabetes'). These findings suggest the possibility of a unified pathogenesis for the various disturbances of calcium/phosphorus metabolism.

We are indebted to the Zilliken Co. of Genoa for putting at our disposal the ATP used in our therapeutic studies.

\section{REFERENCES}

Aballi. A. J., Montero, R., Escobar Acés, A. and Jimenez, J. (1944). Bol. Soc. cubana Pediat. 16, 3.

Albaum. H. G., Hirshfeld, A. and Sobel, A. E. (1952). Proc. Soc exp. Biol. (N.Y.). 79, 238.

Anderson: J., Brewis, E. G. and Taylor, W. (1957). Archives of Disease in Childhood, 32, 114

Bickel, H. (1958). International Symposium on Carbohydrates.

Cooke, R. E., Segar, W. E., Darrow, D. C., Reed, C., Etzwiler, D., Brusilow, S. and Vita, M. (1953). A.M.A. Amer. J. Dis. Child., 86. 611 .

Dent, C. E. (1947). Biochem. J., 41, 240.

de Toni, G. (1957). Int. Z. Vitaminforsch., 28, 57.

de Toni, E. jr. and Giordano, S. (1957). Minerva pediat. (Torino). 9, 903 .

Dickens. F. (1941). Biochem. J., 35, 1011.

Dixon, T. F. and Perkins, H. R. (1952). Ibid., 52, 260.

Durand, P.. Manzini, W., Bruni, R. and Semach, F. (1956). Minerva pediat. (Torimo), 8, 1073.

Fanconi, G. and Spahr, A. (1956). Helv. paediat. Acta. 10. 156.

Forfar, J. O., Balf, C. L., Maxwell, G. M. and Tompsett, S. L. (1956). Lancet, 1,981 .

Freudenbere, E. (1954). Ann. Pediat., 182, 85.

Gittleman, I. F., Pincus, J. B., Schmerzler, E. and Saito, M. (1956). Pediatrics, 18, 721 .

Glanzmann. E., Meier, K. and Walthard, B. (1946). Z. Vitaminforsch., 17, 159.'

Harrison, H. E. (1954). Pediatrics, 14, 285.

and Harrison, H. C. (1941). J. clin. Invest., 20, 47.

- - (1952a). Yale J. Biol. Chem., 24, 273.

- - (1952b). J. Pediat., 41, 756.

Heinz, E., Müller, E. and Rominger, E. (1947). Z. Kinderheilk., 65, 101.

Hofmann-Credner, D., Rupp. W. and Swoboda, W. (1955). Arch. Kinderheilk., 150. 221.

Jeune, H., Charrat, A., Cotte, Y. and Freycon, M. (1958). Personal communication.

Jonxis, J. H P. (1955). Helv. paediat. Acta, 10, 245.

Lamy, M., Rover, P.. Frézal, Y. and Lestradet, H. (1958). Arch. franc. Pédiat., 15, 1.

Leonard, M. F. (1946). J. clin. Endocr. 6, 493

Marks, P. A Hiatt, H. H. and Shorr, E. (1953). J. biol. Chem., $204,175$.

Nordio, S., Semach, F. and Grego, M. (1956). Minerva pediat. (Torino), 8, 868 .

- Segni, G. and Massaccesi. R. (1957). Ibid., 9, 1569.

Papadatos, C. and Klein, R. (1954). J. Clin. Endocr., 14, 653.

Roberts, K. E. and Pitts, R. F. (1953). Endocrinology, 52, 324

Roberts, K. E. and Pitts, R. F. (1953). Endocrinology, 52. 324.
Royer, P., Lestradet, H. and Habib, R. (1958). Arch. franc. Pediat., 15, 896.

Schwarz-Tiene, E., Careddu. P. and Cabassa N. (1957). Minerva pediat. (Torino), 9, 231 .

Sirota, J. H. and Hamerman, D. (1954). Amer. J. Med.. 16. 138.

Stcenbock. H. and Bellin, S. A. (1953). J. biol. Chem., 205, 985.

van Creveld, S. and Arons, P. (1949). Ann. paediat. (Basel), 173, 299.

van Creveld, S. and Arons, P. (1949) Ann. paediat. (Basel), 173, 299 . (1956). J. clin. Endocr., 16, 1374.

Winberg J. and Zetterström, R. (1956). Acta paediat. (Uppsala), 45,96 .

Zetterström, R. and Arnhold. R. G. (1958). Ibid., 47, 107.

Zweymüller, E. (1958). Mod. Probl. Pädiat., 3, 433.

For further details on these studies and further literature the authors wish to refer to their paper (Mimerva pediat. (Torino), 11, 129 (1959)). 